Article

\title{
Scaling-up Sustainable Energy Storage in Developing Countries
}

\author{
Fernando J. de Sisternes ${ }^{1,2, *}$, Heather Worley ${ }^{1}$, Simon Mueller ${ }^{1}$, \\ Thomas Jenkin ${ }^{1,3}$ \\ 1 The World Bank, 1850 I Street NW, Washington, DC 20433, USA \\ 2 MIT Center for Energy and Environmental Policy Research (CEEPR), \\ 77 Massachusetts Avenue, Cambridge, MA 02139, USA \\ 3 Johns Hopkins University, Krieger School of Arts and Sciences-AAP, \\ 1717 Massachusetts Avenue NW, Washington, DC 20036, USA \\ * Correspondence: Fernando J. de Sisternes, Email: fsisternes@worldbank.org.
}

\section{ABSTRACT}

Background: The modularity and universal deployability of certain energy storage and variable renewable energy resources make the combination of these two elements a possible game changer for achieving universal access to electricity in developing countries while simultaneously decarbonizing their electric grids. Recent cost declines in electrochemical batteries have enabled solutions based on batteries and renewables that have proved to be cost-competitive with fossil-based alternatives in a growing number of cases. However, most widely-available battery systems may not be optimal for power systems applications operating under the challenging conditions frequently found in developing countries. Additionally, scaling-up sustainable energy storage in developing countries requires addressing a number of important challenges that are not well understood. The study presented in this article aims at identifying these challenges, and was undertaken in preparation of the Energy Storage Partnership: a consortium of over 30 organizations convened by the World Bank to jointly address them.

Methods: Expert elicitation in combination with a literature review of standards, news articles, vendors' public materials and academic literature.

Results: The study identifies current challenges for scaling up energy storage in developing countries, and presents research and development work to overcome them.

Conclusions: A wide spectrum of research and development actions is required for energy storage to make its full contribution to energy policy objectives in developing countries. Implementing the actions highlighted in this article will require a concerted approach by national governments and stands to benefit substantially from international cooperation.

KEYWORDS: sustainable energy storage; developing countries; batteries; electrification; access; recycling; safety 


\section{ABBREVIATIONS}

VRE, Variable Renewable Energy; ESMAP, Energy Sector Management Assistance Program; WB, World Bank; ESP, Energy Storage Partnership

\section{INTRODUCTION}

Renewable energy-particularly wind and solar power-has become an economically viable option for electricity production in developing countries. However, wind and solar are variable renewable energy (VRE) sources. Their output fluctuates with the instantaneous availability of wind and sunlight-and there is no guarantee that they will be available when they are needed most. Unlocking the full contribution of renewable energy resources to meeting electricity demand requires additional measures for their integration into power systems.

Countries that have pioneered effective and efficient VRE integration strategies are mostly economically developed; feature sufficient dispatchable generation capacity and operational reserves, as well as robust and stable grids; and, in most cases, good interconnections and energy trade agreements with neighboring countries. In these contexts, cost-effective VRE integration strategies focus on the improved use of existing assets combined with enhanced system operations.

However, most developing countries are in a very different position: existing generation capacity is often insufficient to meet growing electricity demand, the grid is often under-developed (both within and between countries), and operators are unable to maintain grid stability due to a lack of adequate control over generation dispatch and poor demand forecasts. Consequently, under these circumstances, increasing amounts of VRE could impact negatively the secure operation of these systems.

This difference in context requires a fresh approach to system integration and system reliability that focuses on the needs of developing countries. Such an approach will likely feature a more prominent role for energy storage as a solution to support system operations and enable the integration of higher renewable shares without increasing operational challenges.

Energy storage can help match VRE supply to electricity demand, for example by storing solar energy mid-day and releasing it after sunset, when demand is often at peak. Combinations of VRE capacity and energy storage - particularly long-duration energy storage—can therefore offer a low-carbon alternative for providing firm capacity to power systems. Most importantly, energy storage can also provide a range of system services, which helps increase the reliability of power systems, especially in developing countries with weak grid infrastructure. Storage solutions can also help improve energy access in remote areas, where grid expansion is not possible or cost-effective. Furthermore, energy storage 
can be part of resilience strategies in the face of increasing extreme weather events.

Energy storage comprises a multitude of different technologies. They are frequently differentiated by the way in which energy is stored, and can differ significantly in round-trip efficiency: thermal (e.g., molten salt storage for heat or ice for cooling), gravitational potential (e.g., pumped storage hydro), kinetic (e.g., flywheels), electro-static (capacitors), electro-chemical (batteries), compressed air (e.g., adiabatic CAES) or chemical (e.g., synthetic fuels). Within each category there are typically several different technologies relying on similar physical principles but with very different properties and levels of maturity.

The category with the widest variety of technologies and the most rapid recent techno-economical progress is electro-chemical storage, i.e., batteries. Particularly lithium-ion (Li-ion) batteries have seen very rapid cost declines as their use has grown exponentially driven by the market for mobile applications, first in electronic devices, and more recently over the last decade in their use in electric vehicles and their hybrid counterparts. In these applications, high energy density (both in terms of mass and volume) is highly desirable and will take priority over other aspects such as high cycle life.

By contrast, stationary battery applications have different use characteristics and thus dictate different priorities for battery properties. For example, weight and volume constraints may be less relevant, while a high cycle life can be crucial to achieve cost-competitiveness in regimes of frequent charging and discharging. Moreover, lithium-ion batteries are not ideally placed to operate under harsh climate conditions without significant cooling - as both very low and high temperatures lead to more rapid cell degradation and reduce cell efficiency though this varies by chemistry. This may negatively impact the ability of some Li-ion technologies to meet the requirements of stationary applications in developing countries that frequently feature harsh climate conditions.

Recognizing the value that battery storage can bring to developing countries' grids, the World Bank has launched a dedicated program to scale-up battery electricity storage solutions in developing countries and has committed to provide USD 1 billion in support of the program. In addition, the World Bank has launched a global Energy Storage Partnership (ESP) to accelerate progress in the availability of sustainable energy storage solutions for developing countries. In the context of the ESP the World Bank conducted an expert elicitation to better understand what the challenges to scale-up energy storage in developing countries are, and the actions that could be taken to address them.

This article describes the main findings of this research, identifying a series of research priorities to address the main challenges to scaling up sustainable energy storage solutions. 


\section{METHODS}

The team conducting the study used a research-based approach combining literature review and expert elicitation. Accordingly, the team initially conducted a literature review of academic papers, news articles and standards to identify the broad set of technologies, uses, challenges and solutions associated with stationary applications of energy storage. There is a significant and rapidly growing literature focusing on the different types of energy storage and their applications and costs (e.g., Akhil et al. 2015 [1], Desmet 2017 [2], IRENA 2017 [3], Martinez Romero et al. 2015 [4] Lazard 2018 [5], Schmidt et al. 2017 [6], Denholm et al. 2010 [7]), the value of energy storage in decarbonizing electric power (e.g., Sepulveda et al. 2018 [8] and De Sisternes et al. 2016 [9]), existing energy storage stationary projects-the U.S. Department of Energy (DOE) maintains a global energy storage database: https://www.energystorage exchange.org/projects (e.g., EIA 2018 [10]), best practices and evolving standards and safety (e.g., DNV-GL 2017 [11]), market barriers and the use of policy incentives (e.g., Elgqvist et al. 2018 [12], Bhatnagar et al. 2013 [13] and Sioshansi et al. 2012. [14]), ownership models and challenges to scaling up energy storage in stationary applications (ADB 2018 [15]). The multiple value streams of energy storage and how to operate storage and create mechanisms to "stack" and capture the social value of energy storage has also received considerable attention (e.g., Sidhu et al. 2018 [16], Strbac et al. 2017 [17], Hledik et al. 2017 [18], Hledik et al. 2018 [19], Byrne et al. 2018 [20], Fitzgerald et al. 2015 [21], Sioshansi et al. 2013 [22] and Denholm et al. 2013 [23]).

However, given the novel interest in stationary energy storage in developing countries-outside of minigrid and island applications (e.g., Micangeli et al. 2017 [24], Ericson et al. 2017 [25], USAID [26], and Barelli et al. 2019 [27]) - there is relatively little information publicly available that is focused on this topic with some notable recent exceptions. These include, for example Few et al. 2018 and 2019 [28,29] who provide many valuable observations and insights about the challenges facing the use of energy storage in developing countries and emerging markets and how they might be addressed; while IRENA (2019) [30] documents a number of renewable projects in developing countries, some of which use energy storage; and Vivid Economics and Faraday Institution (2019) [31] highlight the role of storage in off-grid applications to increase access to electricity and displace diesel consumption. Other recent studies have looked carefully at some of the recycling and other environmental challenges of energy storage systems (e.g., Deghani-Sanij et al. 2019 [32]), relevant to energy storage projects in developing countries. In addition, a number of studies identified mechanisms to overcome some of the potential barriers to the deployment of energy storage, such as the benefits of the availability of affordable wrapped warranties that may apply to both developed and developing countries (e.g., Robson and Bonomi 2018 [33]). The literature review was complemented with an 
expert elicitation, by which the team gathered direct expert opinions on the value and challenges of deploying sustainable energy storage solutions in developing countries.

The literature review informed the identification of existing knowledge gaps, and the preparation of a set of questions (Table 1) to guide the expert interviews. The selection of the pool of experts interviewed was based on a mix of organizations identified in the literature review as being active in the space, and World Bank partners. During the course of the study, the team elicited responses from representatives of over 100 organizations, including: international organizations, energy storage industry associations, energy storage solutions vendors, research laboratories, universities, and electric power utilities. Interviews were conducted over the course of one hour, with follow-up calls to clarify specific points.

Table 1. Set of questions used during the expert elicitation.

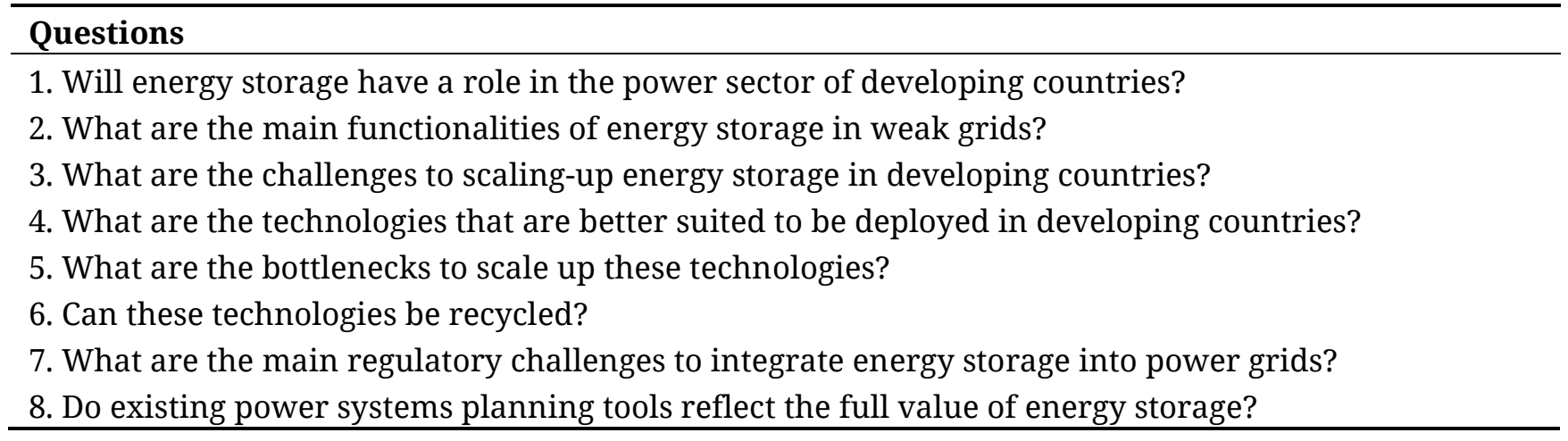

Interviews also included a number of technology specific questions focusing on storage sizing, storage duration, degradation, toxicity, recyclability, operability, availability of materials and technology risks.

\section{RESULTS}

Results fall into two main categories. The first category consists of requirements that need to be met for energy storage to help meet developing countries' objectives. It is natural to frame these in the form of challenges, highlighting those areas where there is currently a gap between what would be needed, and the status quo as found in this study. The second category of results sets out a research and development agenda organized along these challenges, and grouped into four research tracks. These findings represent a synthesis of the ideas identified through the literature review-many of which motivated by ideas laid out in [27] and [28] - and the interviews. Collectively, the analysis proposed under the four tracks can make a significant contribution to overcoming the challenges facing energy storage in developing countries today. 


\section{Main Challenges and Requirements}

The research revealed four main groups of challenges that currently hinder uptake of sustainable energy storage solutions in developing countries:

1. Lack of technology solutions adapted to the needs of developing countries. Current available technology solutions-especially for battery storage systems-are often ill-adapted to developing countries. The systems available are frequently not designed to operate in the often harsh environments of developing countries with extreme temperatures, low capacity to operate and maintain energy storage assets, and reduced access to advanced maintenance tools. In addition, many common technologies rely on relatively rare minerals that could with increased demand increase the cost of battery projects, or have discharge durations that fall short of what is needed for providing firm capacity for longer periods-a requirement that is more frequently found in developing countries. Key technical specifications must be reflected in Bidding Documents to develop a market with technologies that can be sustainably scaled-up. The most relevant attributes-from a pure technology perspective-are summarized in Table 2.

2. Insufficient capacities and skills to evaluate the possible role of energy storage to meet energy policy objectives. Assessing the possible role for energy storage requires an informed approach to system planning that considers multiple options and relies on advanced modelling tools-both at the power system level as well as on the level of modelling individual storage systems. Such tools are frequently not available in developing countries.

3. Non-performant policy, market and regulatory frameworks that hinder revenue certainty and streamlined permitting. Successful project delivery critically depends on securing all required permits and financing. The regulatory environment in many countries lacks clarity/certainty for obtaining permits and bankable remuneration schemes for energy storage do not exist in most cases.

4. Absence of key enabling factors, including trained staff, transportation solutions and recycling systems. Research also revealed a diverse set of additional challenges relating to the absence of crucial enabling factors. For example, availability of trained staff for installation and maintenance of systems was frequently cited as a relevant challenge. In addition, transportation protocols are often not streamlined and/or adhered to, which can lead to batteries arriving damaged. Another important area for sustainable use of energy storage are recycling systems for used batteries. 
Table 2. Attributes of sustainable energy storage technologies.

\begin{tabular}{|c|c|}
\hline Attribute & Description \\
\hline Affordability & Within the financial means of developing countries. \\
\hline Durability & $\begin{array}{l}\text { Ability to deliver power over long periods of time (e.g., for } 4 \text { hours or more duration, } \\
\text { with low annual degradation). }\end{array}$ \\
\hline Operability & $\begin{array}{l}\text { No or very limited need for regular maintenance, nor for highly-qualified personnel to } \\
\text { maintain and operate the energy storage system. }\end{array}$ \\
\hline Robustness & $\begin{array}{l}\text { Designed to operate above } 50^{\circ} \mathrm{C} \text {, and avoid irreversible damage after disruptions in } \\
\text { the cooling system, and/or operate in extreme environments. }\end{array}$ \\
\hline $\begin{array}{l}\text { Availability of } \\
\text { materials }\end{array}$ & $\begin{array}{l}\text { Availability of sufficient quantity of material to scale-up deployment and diversify } \\
\text { origin to avoid supply disruptions and price volatility. }\end{array}$ \\
\hline Safety & $\begin{array}{l}\text { Stability of the materials used, and ability to isolate failure within secondary } \\
\text { containment in case of fire, mechanical/chemical explosion or leakage. }\end{array}$ \\
\hline Low Toxicity & $\begin{array}{l}\text { Not containing elements that cannot be disposed in a landfill, that would become a } \\
\text { hazard if spilled, or that emit toxic gases as a by-product of the reactions inside the } \\
\text { energy storage equipment. }\end{array}$ \\
\hline Recyclability & $\begin{array}{l}\text { Ability to extract and reuse high salvage value materials from the energy storage } \\
\text { equipment. }\end{array}$ \\
\hline
\end{tabular}

Based on the four groups of challenges described and desirable attributes shown in Table 2, the team organized the full list of research topics identified along four tracks focused on "Technology RD\&D, Applications and Standards” (Track 1); "System Integration and Planning Tools” (Track 2); "Policies, Regulation and Procurement” (Track 3); and "Enabling Systems for Management and Sustainability" (Track 4) .The main items along the four tracks are briefly summarized in Figure 1.

Track 1 - Technology
RD\&D, Applications and
Standards
- New applications and
technology solutions for
challenging environments
- Technology research,
development \&
demonstration (e.g. testbed)
- Performance and safety
standards
- Recycling standards
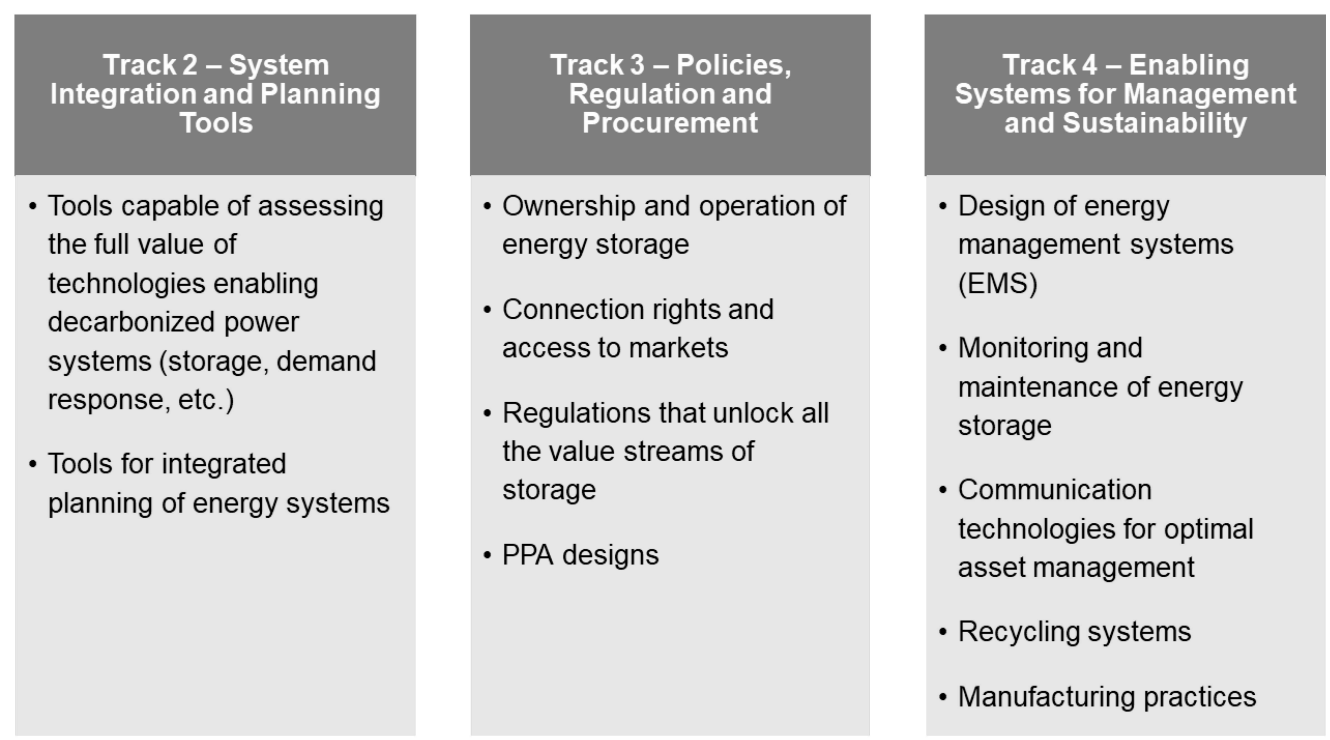

Figure 1. Summary of the main research tracks proposed and the main items within each track. 
In the remainder of this section, the four tracks and related analysis is presented in more detail.

\section{Research Track 1: Technology Research, Development \& Demonstration, Applications}

Research along this track aims to increase understanding of the technical specifications required by energy storage solutions for power system applications in developing countries and increase the availability, commercial maturity, and affordability of such solutions. It can be further segmented into three areas: adaptation of mature technologies; research, demonstration and development of new technologies; development of standards, quality assurance mechanisms, testing and labels.

Adaptation of mature energy storage technologies and their application in developing countries

- Optimized containerized solutions for energy storage systems: This topic encompasses activities regarding the development, testing and deployment of ready-to-use, containerized solutions for energy storage. These solutions should be easily transportable, highly robust, withstand harsh climatic conditions, non-toxic, highly recyclable, and require little maintenance in the field.

- Advanced use of thermal energy storage in concentrating solar power plants and beyond: Many developing countries have excellent solar resources with potential for concentrating solar power (CSP) applications. Combined with thermal energy storage, CSP is an efficient way to meet demand after sunset, including for durations of 5-10 hours or more. Work under this topic can highlight the possible benefits of CSP with thermal storage and provide up-to-date information on cost and performance characteristics. Other thermal storage applications for RE power could also be explored.

- Optimizing operation and maintenance strategies for energy storage systems: Work on this topic could focus on gaining an improved understanding of main drivers for O\&M costs and asset degradation in developing countries. Building on this, it would be possible to derive and disseminate improved strategies to minimize O\&M costs and asset degradation while maximizing asset availability.

Research, demonstration and development of new technologies

- Program to expand knowledge about next-generation technologies: The current market for batteries is dominated by Li-Ion-technologies, developed originally for applications in electric vehicles and consumer electronics. However, these may not be the technologies or chemistries best-suited for the power sector, especially in some developing countries. There is a need to improve awareness of the 
suite of existing and emerging battery technologies on the market, and to establish clear criteria to assess their maturity. Work on this topic could enhance understanding of relevant technologies including certain types of flow, zinc-air, and sodium-sulfur batteries, among others, and their appropriateness for developing countries' power systems.

- Accelerate the uptake of hybrid technology energy storage systems: Different storage technologies have different strengths in terms of technical characteristics, most notably the ratio at which energy and capacity and related charge and discharge rates can be provided to the system. Packaging solutions using different technologies can help to combine different technologies' strengths, meeting different applications, while minimizing weaknesses. Work on this topic could feature the deployment of such hybrid systems in practice (e.g., Zinc or flow battery for energy and Li-ion for power; or Li-ion in combination with a mechanical flywheel to reduce the number of cycles performed by the battery and extend its lifespan).

- Promising new chemistries, cost-reduction potential, and hydrogen: Exploring new battery chemistries and hybrids is an active field of basic and applied research. In addition, hydrogen and its derivatives are receiving increasing attention, particularly given the possibility of using renewable-generated hydrogen to produce synthetic fuels for building, transport and industrial applications ("Sector coupling" refers to the idea of interconnecting different energy consuming sectors, such as buildings (heating and cooling), transport, and industry, with the electric power sector. Sector coupling offers the opportunity to increase the utilization of capex-intensive assets, reducing their average cost). Work under this topic could feature a systematic assessment of cost reduction opportunities for different storage technologies or chemistries for a range of applications in developing countries. Additional work could focus on the identification of and research on emerging battery chemistries that are tailored to developing country needs, e.g., using common raw materials such as zinc, sodium and iron, that are non-toxic, abundant and/or have no or low thermal cooling requirements for systems installed in high-temperature environments.

Development of standards, quality assurance mechanisms, testing and labels

- Quality assurance processes to guarantee performance in real-world conditions: There is often a large discrepancy between claimed performance of energy storage systems and what is observed under real-world conditions. Standards and labels that rely on testing procedures that accurately reflect operating conditions are needed. As part of the work on this topic, performance and operational characteristics for new and existing energy storage systems could be 
assessed under challenging environmental conditions (e.g., in a dedicated storage technologies' testbed). Based on this, it would be possible to establish labels/standards including for: (i) safety and thermal stability under high temperature operations, (ii) low degradation under deep and frequent cycling, (iii) system efficiency including parasitic losses, including how those losses vary with external temperature, (iv) resilience, and (v) low maintenance requirements.

- Warranties suited for applications in developing countries: Existing warranties for energy storage systems are frequently ill-adapted for applications in developing countries. This includes unclear responsibilities in case of faults/failures or clauses that excessively limit the operational envelope of the asset, and temperature limits that may fall below the unshaded temperature variation in some countries. Work under this topic could aim to develop affordable fully wrapped/single point of contact warranty packages for harsh environmental conditions. It could also help to ensure that flexible operation of storage assets is not unduly penalized by warranty specifications. Work on this topic should also aim to increase transparency of warranties.

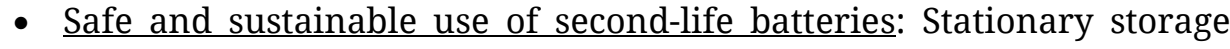
applications using batteries that were previously used in other applications (e.g., electric mobility) is a promising option to reduce costs and enhance sustainability. However, making such use effective and sustainable requires safeguards to ensure that second-life batteries meet performance requirements in developing countries and can make a valuable contribution to power systems, rather than being used as an indirect way to dispose low-grade batteries. Work on this topic could establish guidelines on the safe and sustainable use of second-life batteries and potentially test these in the field.

\section{Research Track 2: System Integration and Planning Tools}

Optimizing the size and operation of energy storage in a power system requires appropriate planning using system modelling tools that reflect both energy storage systems themselves as well as the power systems in which they operate. While the past years have seen significant progress in the improvement of power system models and tools, this process is far from being completed given the significant challenges of processing much higher resolution data. Hence, this research track is directed towards developing models to support technology selection, and optimal sizing in terms of power capacity (kW or MW), energy capacity (kWh or MWh) and duration (hours), and (dis)charge rates-with a clear emphasis on capturing renewable variability and the specific needs of energy storage in developing countries. The track can be further differentiated into research aimed at improving modelling tools for (1) the overall power system and (2) energy storage system modeling tools. 


\section{Power system modeling tools}

- Integrated modeling tools, valuation frameworks and cost/benefit methodologies: There is currently no standard methodology available to comprehensively capture the possible system benefits of storage in a consistent valuation framework that reflects how the storage asset will be operated to provide multiple services. There is also a lack of standardized methodologies for cost-benefit analysis to assess the system value of energy storage under existing regulatory frameworks. Work under this topic could further improve the availability of power system modelling and cost benefits analysis tools. This work would also need to recognize the impact of data and resource limitations, and how these may vary depending on the size of the project.

- Capturing stability in operational models and improved ancillary services modeling: One field of model development that is particularly relevant for developing countries that often feature small power systems with weak grids is the improved integration of (a) models that assess operational dynamics (production cost models) and (b) models to analyze power system stability. Integrating a reasonable approximation of the voltage and angle stability phenomena in a production costing model could help to appropriately value the contribution of storage to mitigating challenges of integrating VRE. In addition, such models could be used to better understand what different types of frequency- and voltage-control services such systems require and could derive standard practices for the sizing and modeling of such services.

- Enhanced micro- and mini-grid models for developing countries: Micro- and mini-grids are particularly relevant for providing clean energy access in rural communities. Modeling these systems requires a sufficient level of granularity in representing generators and loads. This topic aims at screening available system integration and planning tools for mini-grids and small grids, looking at least-cost optimization models that capture all value streams (including peak load shifting, firm capacity, reserves, voltage support, black start), offering a comprehensive modeling tool. Such a screening could also consider implementation and human resource constraints of developing countries in the model assessment, including human capital (training and workload to run models) and data requirements.

- Tools for optimizing hybrid renewables plus storage plants: Deploying integrated solutions for hybrid renewables plus storage plants can bring a number of benefits, including reduced complexity in project development and a good match between the generation and storage system. Such hybrid systems can also be optimized to reduce or eliminate the need for thermal backup depending on reliability considerations. Work as part of this topic could focus on the development/dissemination of (open-source) tools to calculate the optimal combination of renewables plus storage systems. 


\section{Energy storage system modeling tools}

- Model benchmarking and calibration against real-world projects: Modeling of energy storage systems requires sufficient knowledge of a variety of techno-economic parameters. Model results will match operational reality only if parameters are accurately set, which can be difficult for newer technologies or chemistries where there may be significant uncertainty in how parameters may change over time with use. This topic aims at analyzing and possibly improving the model representation of energy storage systems by benchmarking and calibrating techno-economic energy storage models and parameters against real projects in developing countries. Parameters may be disseminated in a database updated regularly.

- Dispatch optimization models for energy storage systems: Energy storage is prized for its versatility and wide-range of possible usage patterns that may support multiple applications. However, this also means that finding an optimal usage pattern for an energy storage system can be a quite complex task, requiring decisions on how to manage charging and discharging times, etc. Hence, models and software are needed to determine the optimal operational schedule of energy storage systems, reflecting realistic operational constraints, value stacking, and the impact of uncertainty. Ideally, such models are capable to find optimal solutions in both cost of service and market-based remunerations.

- Standard representation/parameters for energy storage in power system models: As storage becomes more common in power systems, models for power system planning and operation need to accurately capture the techno-economic properties of a growing suite of energy storage technologies. This task aims at reviewing existing sources for techno-economic parameters for energy storage, with the aim of developing standard representations of different energy storage technologies such as degradation with use, which can be used in a wide range of different power system models.

\section{Research Track 3: Policies, Regulation, and Procurement}

Research along this track aims to increase understanding of the policy, market, regulatory, and procurement frameworks applicable to energy storage solutions for grid applications in developing countries. Because this track relates to instruments that directly target deployment, learning in this field will be very closely linked to technology deployment. The following topics have been identified:

- Policy toolbox for supporting energy storage: The success of renewable energy is closely linked with policy tools that supported their market introduction at scale (e.g., grants, feed-in tariffs, quota systems, etc.). While such tools cannot be applied directly to energy storage, the adaptation of existing policy instruments-combined with 
the design of innovative instruments-could facilitate the accelerated uptake of storage, including in developing countries. Work on this topic could focus on a review of existing policy instruments applied for renewable energy and their applicability for energy storage.

- Cataloging project development barriers and proposing solutions: The development of energy storage projects requires a large number of steps from a first idea all the way to a commissioned project. Because storage is new in many developing countries, permitting process are often unclear, can involve multiple agencies and thus require significant time and effort. Work on this task could collect relevant barriers for project development in selected countries and could propose solutions for more streamlined permitting.

- Adapting national policy and regulatory frameworks for battery storage: Regulators around the world are currently grappling with the challenges and opportunities brought by energy storage. Work as part of this topic could feature ways in which storage can be included in national energy policies, and an analysis of how regulators can manage battery electricity storage in power sector governance, based on recent international experience that is relevant for developing countries. Such a publication could also include a clear definition of system services for storage, ways to measure performance and guidance for remuneration. An additional step to make progress in this area is to promote regulations to use existing local repair networks in extending useful life of storage systems and subcomponents.

- Improved access to financing: Financial institutions have a direct impact on the viability of energy storage projects by determining the cost at which projects can access financing. In turn, financial institutions require appropriate knowledge and tools for a sound appraisal of project risks. Work under this topic is aimed at strengthening this capacity among financial institutions. This could be achieved by developing and disseminating primers and online learning resources for financial institutions focused on energy storage systems.

- Procurement instruments for standard applications: The design of procurement instruments such as auctions and/or power and service purchase agreements (PSPAs) will have a decisive influence on the success or failure of accelerating energy storage deployment in developing countries. Standard procurement instruments applied across countries could help reduce transaction costs and accelerate progress. Work on this topic could include development of standard PSPAs between public utilities and energy storage/energy companies. These could feature a limited set of standard specifications/ requirements that are tailored to typical use cases in developing countries to reduce transaction costs and enhance price transparency (comparability across different projects). Such standard instruments 
should also include appropriate safeguards to ensure project sustainability. Outputs for this topic could include sample agreements, auction design rules and best-practice manuals and guidelines for policy makers.

- Standard procurement for hybrid solutions: Packaging energy storage and renewable energy power plants can bring a number of advantages. This raises the question on how to best procure such hybrid options. There is little international experience in this area and work on this task could aim at providing a comprehensive collection of existing approaches as well as proposing ideas on how to procure hybrid plants. Outputs for this topic could include sample agreements, auction design rules and best-practice manuals and guidelines for policy makers.

- Business models for storage-enabled energy access: The combination of distributed renewable energy and storage is a powerful tool for enabling energy access especially in remote communities. In principle, private sector players could play a role for driving progress in this area. However, developing and implementing appropriate business models can be challenging-relevant issues include financing of the initial investment, establishing payment systems that ensure reliable revenue collection and dealing with the possible connection of the community to the public grid after project commissioning. Work on this topic could review existing business models for storage enabled energy access, disseminate good practice and propose possible innovations.

- National and regional energy storage strategies and roadmaps: A clear vision for the role of storage in the energy system is indispensable for designing appropriate policy tools and growing national and regional markets for energy storage. Such a vision can be developed and articulated in different ways, for example via a national strategy document or as part of a roadmapping process. Work on this topic could feature identifying relevant analysis and stakeholder engagement in support of developing strategies and roadmaps.

- Monitoring system for storage procurement instruments: The experience with renewable energy policy demonstrates that there is substantial value in learning from the experiences of other jurisdictions in policy design and implementation. However, this requires the timely availability of data on the design and real-world performance of different procurement instruments. Work as part of this topic could feature the establishment of a policy tracker for energy storage procurement with a focus on developing countries. Research outputs for this topic could include sample agreements, auction design rules and best-practice manuals and guidelines for policy makers. 


\section{Research Track 4: Enabling Systems for Management and Sustainability}

There are several enabling systems and infrastructure needs without which deployment of energy storage will be slower, costlier, and less sustainable. Such systems include supplementary systems needed for efficient operation (e.g., systems to monitor and operate the broader power system, cooling systems, etc.), recycling systems, as well as the presence of local industries, well-trained local staff, and manufacturing practices that bring added value for developing countries and communities. Along this track activities aim to highlight the opportunities for establishing parts of the energy storage value chain in developing countries, while increasing the capacity of local staff and improving the design and availability of systems required for the sustainable, long-term deployment of energy storage.

- Capacity building and regulation for installation, operation, and maintenance: Successful implementation of energy storage projects-during both construction and operation-critically depends on the availability of qualified staff. Sourcing this staff from local labor markets can contribute to sustainable economic development in developing countries. In turn, this requires that local staff is appropriately trained in energy storage system installation, operation \& maintenance. This topic aims at improving this situation via identification of appropriate capacity building measures. An additional step to make progress in this area is to assess options to promote regulations to use existing local repair networks in extending useful life of storage systems and subcomponents.

- Commercialization of simple and robust energy management systems: Energy management systems (EMSs) are a combination of hardware (sensors, telecommunication equipment, computers etc.) and software (optimization tools etc.) that allow remote and automated optimization of operation, monitoring and maintenance of energy storage systems. Many systems available on the market today are not optimized for the needs of developing countries. Work under this topic aims to identify and make available EMSs that are affordable and robust while providing core functionalities required for successfully operating energy storage systems.

- Transportation, warehousing and installation: Energy storage systems, especially batteries, require certain measures during transport, warehousing and installation to guarantee their proper functioning when the system begins operation. For example, if a batteries' state of charge falls below a certain threshold as a result of too long warehousing without charging the battery, it may suffer irreversible damage. Similar considerations may apply during transport and installation and potential exposure to extreme temperatures or humidity. Developing countries often lack knowledge in this area, 
which can compromise project success or lead to unnecessary cost increases. Work under this topic could develop and disseminate clear guidelines for timely and appropriate transportation, warehousing and logistics.

- Deployment of communication and information technology to facilitate storage uptake: Using VRE power plants and energy storage systems to their full potential requires a more sophisticated approach to power system operation compared to legacy technologies such as diesel generators. Consequently, supervisory control and data acquisition (SCADA) systems and similar equipment need to be present in the power system and the local system operator needs to have sufficient capacity for operating such systems. Work under this task aims at identifying digital monitoring and control equipment (such as SCADA systems) solutions for developing countries in order to facilitate the use of VRE and storage.

- Best practice guidelines for cooling systems and other auxiliary systems: Due to the limited experience of many project developers with battery deployment and operation in the climatic conditions of developing countries, there can be a lack of understanding how to best balance reliability and cost for battery storage systems. This topic is aimed at sharing best practices on how to approach the dimensioning and optimization of relevant auxiliary systems for battery projects, including but not limited to cooling. In particular, understanding how the overall system efficiency, including cooling loads varies for different battery chemistries in hot climates.

- Recycling systems and standards: An efficient and effective recycling system is indispensable for making energy storage deployment in developing countries environmentally sustainable. Many battery technologies contain toxic materials that require appropriate handling for disposal and recycling. Failure to establish recycling systems could severely undermine the credibility of energy storage for sustainably meeting energy policy objectives. Work as part of this topic could target all or a subset of the following issues: identification of technology attributes most relevant for environmental sustainability, taking stock of current recycling practices, identifying successful models for recycling systems, disseminate information on such models, assist countries in the implementation and monitoring of recycling systems.

\section{DISCUSSION}

The results of this study demonstrate that a wide spectrum of actions is required for energy storage to make its full contribution to energy policy objectives in developing countries. As the grouping around different tracks highlights, research and development requirements cover the entire value chain. This starts with availability of suitable technologies, which calls for adapting existing technologies and 
supporting the development and testing of novel chemistries and designs. But even if these were available, deployment in developing countries would still require improved modelling capabilities in order to choose appropriate solutions (Track 2) as well as a supportive procurement, policy and regulatory framework (Track 3). Finally, making such deployment environmentally, socially and economically sustainable further requires progress in recycling systems, identifying opportunities for local value creation, and improved operation and maintenance strategies (Track 4).

It is worth highlighting that already the adaptation of existing technologies—combined with actions along Tracks 2-4-could unlock a meaningful contribution from energy storage. Efforts in this direction can bring a double benefit. Firstly, adaptation of established technologies implies that technology development will not be a relevant bottleneck and benefits can accrue to countries more quickly. Secondly, they allow establishing all required components of the value chain to enable deployment in a given developing country. Innovative solutions can then be rolled out much more quickly once available, because the relevant "enabling infrastructure" is already established.

Implementing the various research and development actions highlighted in this article will require a concerted approach by national governments-in industrialized as well as developing countries-and stands to benefit substantially from international cooperation. Facilitating such an approach is at the center of the World Bank's Energy Storage Partnership (ESP). The ESP functions as a platform for exchange between governments, private companies, academia, government- and non-government organizations, independent experts and representatives of civil society to accelerate progress for energy storage along the four tracks identified in the research for this study.

\section{CONCLUSIONS}

Renewable energy-particularly wind and solar power-has become an economically viable option for electricity production in developing countries. Developing countries generally feature insufficient grid and power generation infrastructure. Consequently, energy storage is likely to play a more important role for system integration of variable sources of electricity.

This study relied on a combination of literature review and expert elicitation via interviews with representatives of over 100 organizations to identify current challenges for energy storage in developing countries, and propose research and development work that can contribute to overcoming these challenges. Challenges can be summarized along six properties that storage technologies need to meet for a sustainable deployment, but which are still challenging to obtain at reasonable costs in the market: recyclability, low toxicity, safety, accessibility, robustness, and operability. This study presents research and development work, 
organized into four main tracks that can help to overcome aforementioned challenges. The tracks are: (1) Technology Research, Development \& Demonstration, Applications; (2) System Integration and Planning Tools; (3) Policies, Regulation, and Procurement; (4) Enabling Systems for Management and Sustainability.

The results of this study demonstrate that a wide spectrum of actions is required for energy storage to make its full contribution to energy policy objectives in developing countries. However, this does not mean that deployment needs to wait until new technologies become available. In addition to its direct benefits, the deployment of appropriately adapted existing technologies in developing countries can help to establish the required parts of the value chain there. In turn, this allows a fast-tracked deployment also of innovative solutions once these become commercially available.

Implementing the various research and development actions highlighted in this article will require a concerted approach by national governments-in industrialized as well as developing countries-and stands to benefit substantially from international cooperation.

\section{AUTHOR CONTRIBUTIONS}

FdS and HW designed the study and conducted the interviews, TJ conducted the literature review, SM drafted the description of the research tracks based on outputs from the interviews and the literature review, all authors contributed to the identification of research topics and writing the article.

\section{CONFLICTS OF INTEREST}

The authors declare that there is no conflict of interest.

\section{FUNDING}

The work presented in the article was funded by the World Bank's Energy Sector Management Assistance Program (ESMAP). ESMAP is a partnership between the World Bank Group and 18 partners to help low and middle-income countries reduce poverty and boost growth, through environmentally sustainable energy solutions. ESMAP's analytical and advisory services are fully integrated within the World Bank Group's country financing and policy dialogue in the energy sector.

\section{ACKNOWLEDGMENTS}

The authors wish to thank ESP partners, organizations interviewed and peer reviewers for their inputs. The authors also wish to thank the following individuals for their inputs throughout the period leading to the first meeting of the ESP: Zuzana Dobrotkova, Chandrasekar Govindarajalu, Rohit Khanna, Sandra Chavez, Pierre Audinet, Manuel 
Millan, Chong Suk Song, Phillip Hannam, Silvia Martinez, and Tarek Keskes.

\section{REFERENCES}

1. Akhil AA, Huff G, Currier AB, Kaun BC, Rastler DM, Chen SB, et al. DOE/EPRI Electricity storage handbook in collaboration with NRECA. Albuquerque (US): Sandia National Laboratories; 2015. doi: 10.2172/1170618

2. Desmet J. Valuing dedicated storage in electricity grids. European Academies Science Advisory Council (EASAC) policy report 33. Halle (Germany): EASAC; 2017. Available from: https://biblio.ugent.be/publication/8532053/file/8532059. Accessed 2019 Nov 13.

3. IRENA. Electricity storage and renewables: costs and markets to 2030. Abu Dhabi (United Arab Emirates): IRENA; 2017. Available from: http://www.irena.org///media/Files/IRENA/Agency/Publication/2017/Oct/IREN A Electricity Storage Costs 2017.pdf. Accessed 2019 Nov 13.

4. Martinez Romero S, Hughes W. Bringing variable renewable energy up to scale: options for grid integration using natural gas and energy storages. Washington, DC (US): The World Bank Group; 2015. Available from: https://openknowledge.worldbank.org/bitstream/handle/10986/21629/ESMAP BringingVariableRenewableEnergyUptoScale VRE TR006-15.pdf?sequence $=4$. Accessed 2019 Nov 13.

5. Lazard. Lazard's Levelized cost of storage analysis V4.0. New Orleans (US): Lazard; 2018. Available from: https://www.lazard.com/media/450774/ lazards-levelized-cost-of-storage-version-40-vfinal.pdf. Accessed 2019 Nov 13.

6. Schmidt O, Hawkes A, Gambhir A, Staffell I. The future cost of electrical energy storage based on experience rates. Nat Energy. 2017;2(8):17110.

7. Denholm P, Ela E, Kirby B, Milligan M. Role of energy storage with renewable electricity generation. Golden (US): National Renewable Energy Lab. (NREL); 2010. doi: 10.2172/972169

8. Sepulveda NA, Jenkins JD, de Sisternes FJ, Lester RK. The role of firm low-carbon electricity resources in deep decarbonization of power generation. Joule. 2018;2(11):2403-20. doi: 10.1016/j.joule.2018.08.006

9. De Sisternes FJ, Jenkins JD, Botterud A. The value of energy storage in decarbonizing the electricity sector. Appl Energy. 2016;175:368-79. doi: 10.1016/j.apenergy.2016.05.014

10. EIA. U.S. Battery storage market trends. Washington, DC (US): U.S. Energy Information Administration; 2018 May. Available from: https://www.eia.gov/analysis/studies/electricity/batterystorage/pdf/battery st orage.pdf. Accessed 2019 Nov 13.

11. DNV GL. Recommended practice: Safety, operation and performance of grid-connected energy storage systems. DNVGL-RP-0043. Oslo (Norway): DNV GL; 2017. Available from: http://rules.dnvgl.com/docs/pdf/DNVGL/RP/ 2017-09/DNVGL-RP-0043.pdf. Accessed 2019 Nov 13.

12. Elgqvist EM, Anderson KH, Settle DE. Federal tax incentives for energy storage systems. Golden (US): National Renewable Energy Lab. (NREL); 2018. 
Available from: https://www.nrel.gov/docs/fy18osti/70384.pdf. Accessed 2019 Nov 13.

13. Bhatnagar D, Currier A, Hernandez J, Ma O, Kirby B. Market and policy barriers to energy storage deployment. Albuquerque (US): Sandia National Lab. (SNL-NM); 2013. doi: 10.2172/1096462

14. Sioshansi R, Denholm P, Jenkin T. Market and policy barriers to deployment of energy storage. Econ Energy Environ Policy. 2012;1(2):47-64. doi: 10.5547/2160-5890.1.2.4

15. ADB. Handbook on battery energy storage system. Mandaluyong (Philippines): Asian Development Bank; 2018. Available from: https://www.adb.org/sites/default/files/publication/479891/handbook-battery -energy-storage-system.pdf. Accessed 2019 Nov 13.

16. Sidhu AS, Pollitt MG, Anaya KL. A social cost benefit analysis of grid-scale electrical energy storage projects: A case study. Appl Energy. 2018;212:881-94. doi: 10.1016/j.apenergy.2017.12.085

17. Strbac G, Aunedi M, Konstantelos I, Moreira R, Teng F, Moreno R, et al. Opportunities for energy storage: assessing whole-system economic benefits of energy storage in future electricity systems. IEEE Power Energy Mag. 2017;15(5):32-41. doi: 10.1109/MPE.2017.2708858

18. Hledik R, Lueken R, McIntyre C, Bishop H. Stacked benefits: comprehensively valuing battery storage in California. Prepared for Eos Energy Storage. Boston (US): The Brattle Group; 2017. Available from: http://files.brattle.com/system/publications/pdfs/000/005/494/original/stacked benefits - final report.pdf. Accessed 2019 Nov 13.

19. Hledik R, Chang J, Lueken R, Pfeifenberger J, Pedtke JI, Vollen J. The economic potential for energy storage in Nevada. Prepared for Public Utilities Commission of Nevada Governor's Office of Energy. Boston (US): The Brattle Group; 2018. Available from: http://files.brattle.com/files/14618 economic potential for storage in nevada - final.pdf. Accessed 2019 Nov 13.

20. Byrne RH, Nguyen TA, Copp DA, Chalamala BR, Gyuk I. Energy management and optimization methods for grid energy storage systems. IEEE Access. 2017;6:13231-60. doi: 10.1109/ACCESS.2017.2741578

21. Fitzgerald G, Mandel J, Morris J, Touati H. The economics of battery energy storage: How multi-use, customer-sited batteries deliver the most services and value to customers and the grid. Colorado (US): Rocky Mountain Institute; 2015. p. 6. Available from: https://rmi.org/wp-content/uploads/ 2017/03/RMI-TheEconomicsOfBatteryEnergyStorage-FullReport-FINAL.pdf. Accessed 2019 Nov 13.

22. Sioshansi R, Madaeni SH, Denholm P. A dynamic programming approach to estimate the capacity value of energy storage. IEEE Trans Power Syst. 2013;29(1):395-403. doi: 10.1109/TPWRS.2013.2279839

23. Denholm P, Jorgenson J, Hummon M, Jenkin T, Palchak D, Kirby B, et al. Value of energy storage for grid applications. Golden (US): National Renewable Energy Lab. (NREL); 2013. doi: 10.2172/1079719 
24. Micangeli A, Del Citto R, Kiva I, Santori S, Gambino V, Kiplagat J, et al. Energy production analysis and optimization of mini-grid in remote areas: the case study of Habaswein, Kenya. Energies. 2017;10(12):2041. doi: 10.3390/en10122041

25. Ericson SJ, Rose E, Jayaswal H, Cole WJ, Engel-Cox J, Logan J, et al. Hybrid storage market assessment: A JISEA white paper. Golden (US): National Renewable Energy Lab. (NREL); 2017. doi: 10.2172/1399357

26. USAID. What ownership models are used for mini-grids? Washington, DC (US): USAID; 2018. Available from: https://www.usaid.gov/energy/mini-grids/ ownership/models. Accessed 2019 Nov 13.

27. Barelli L, Bidini G, Cherubini P, Micangeli A, Pelosi D, Tacconelli C. How hybridization of energy storage technologies can provide additional flexibility and competitiveness to microgrids in the context of developing countries. Energies. 2019;12(16):3138. doi: 10.3390/en12163138

28. Few S, Schmidt O, Gambhir A, Stephenson E, DelCore A. Energy storage trends for off-grid services in emerging markets. London (UK): Shell Foundation; Grantham Institute; Imperial College; 2018. Available from: https://shellfoundation.org/app/uploads/2018/10/Shell-Foundation Energy-St orage-Report.pdf. Accessed 2019 Nov 13.

29. Few S, Schmidt O, Gambhir A. Energy access through electricity storage: Insights from technology providers and market enablers. Energy Sustain Dev. 2019;48:1-10. doi: 10.1016/j.esd.2018.09.008

30. IRENA/ADFD. Advancing renewables in developing countries: progress of projects supported through the IRENA/ADFD project facility. Abu Dhabi (United Arab Emirates): IRENA/ADFD; 2019. Available from: https://www.irena.org/publications/2019/Jan/Advancing-Renewables-in-Deve loping-Countries. Accessed 2019 Nov 13.

31. Vivid Economics; Faraday Institution. Rapid market assessment of energy storage in weak and off-grid contexts of developing countries. London (UK): Vivid Economics; 2019. Available from: https://faraday.ac.uk/wp-content/ uploads/2019/10/191025-Rapid-market-assessment-of-storage-in-developingcountries.pdf. Accessed 2019 Nov 13.

32. Dehghani-Sanij AR, Tharumalingam E, Dusseault MB, Fraser R. Study of energy storage systems and environmental challenges of batteries. Renew Sustain Energy Rev. 2019;104:192-208. doi: 10.1016/j.rser.2019.01.023

33. Robson P, Bonomi D. Growing the battery storage market. Exploring four key issues. In: From the Producers of the Energy Storage World Forum. Singapore (Singapore): Dufresne, Energy Storage World Forum; 2018. Available from: https://energystorageforum.com/files/ESWF Whitepaper Growing the battery storage market full.pdf. Accessed 2019 Nov 13.

How to cite this article:

De Sisternes FJ, Worley H, Mueller S, Jenkin T. Scaling-up Sustainable Energy Storage in Developing Countries. J Sustain Res. 2020;2(1):e200002. https://doi.org/10.20900/jsr20200002 